NOTE

\title{
In vitro toxicity of bithionol and bithionol sulphoxide to Neoparamoeba spp., the causative agent of amoebic gill disease (AGD)
}

\author{
Renee L. Florent ${ }^{1}$, Joy A. Becker ${ }^{1,2}$, Mark D. Powell ${ }^{1,3, *}$ \\ ${ }^{1}$ Aquafin CRC, National Centre for Marine Conservation and Resource Sustainability, University of Tasmania, \\ Locked Bag 1370 Launceston, Tasmania 7250, Australia \\ ${ }^{2}$ Faculty of Veterinary Science, University of Sydney, 425 Werombi Road, Camden, NSW 2570, Australia \\ ${ }^{3}$ Faculty of Biosciences and Aquaculture, Bodø University College, Postboks 1490, Bodø, N-8049, Norway
}

\begin{abstract}
The objective of the present study was to evaluate the in vitro toxicity of bithionol and bithionol sulphoxide to Neoparamoeba spp., the causative agent of amoebic gill disease (AGD). The current treatment for AGD-affected Atlantic salmon involves bathing sea-caged fish in freshwater for a minimum of $3 \mathrm{~h}$, a labour-intensive and costly exercise. Previous attempts to identify alternative treatments have suggested bithionol as an alternate therapeutic, but extensive in vitro efficacy testing has not yet been done. In vitro toxicity to Neoparamoeba spp. was examined using amoebae isolated from the gill of AGD-affected Atlantic salmon and exposing the parasites to freshwater, alumina $\left(10 \mathrm{mg} \mathrm{l}^{-1}\right)$, seawater, bithionol or bithionol sulphoxide at nominal concentrations of $0.1,0.5,1,5$ and $10 \mathrm{mg} \mathrm{l}^{-1}$ in seawater. The numbers of viable amoebae were counted using the trypan blue exclusion method at $0,24,48$ and $72 \mathrm{~h}$. Both bithionol and bithionol sulphoxide demonstrated in vitro toxicity to Neoparamoeba spp. at all concentrations examined (0.1 to $10 \mathrm{mg} \mathrm{l}^{-1}$ over $72 \mathrm{~h}$ ), with a comparable toxicity to freshwater observed for both chemicals at concentrations $>5 \mathrm{mg} \mathrm{l}^{-1}$ following a $72 \mathrm{~h}$ treatment. Freshwater remained the most effective treatment, with only $6 \%$ viable amoebae seen after $24 \mathrm{~h}$ and no viable amoebae observed after $48 \mathrm{~h}$.
\end{abstract}

KEY WORDS: Amoebic gill disease · AGD - Bithionol · In vitro · Toxicity · Neoparamoeba spp. · Atlantic salmon $\cdot$ Chemotherapy $\cdot$ Protozoan parasite

\section{INTRODUCTION}

Bithionol, 2,2'-thiobis (4,6-dichlorophenol), and bithionol sulphoxide, bis (2-hydroxy-3,5-dichlorophenyl) sulphoxide, are anthelmintics that are known to uncouple electron transport (Rew 1978), act on the mitochondrial respiratory chain (Iglesias et al. 2002) and aid in the suppression of adenosine-5'-triphosphate (ATP) synthesis via uncoupling of oxidative phosphorylation (Harder 2002). They are also reported to be halogenated anti-infective agents that are used against trematode and cestode infestations in humans (Harder 2002). Bithionol has been reported as effective for the treatment of metagonimiasis and paragonimiasis in humans, and for killing the trematodes in vitro (Yokogawa et al. 1961a,b, Sawatari \& Hamajima 1967). Furthermore, bithionol is reported to kill the human parasite Entamoeba histolytica in vitro and was able to inhibit endogenous and 2-propanol-supported respiration, but not the formation of ethanol in the parasite (Takeuchi et al. 1984). Bithionol and bithionol sulphoxide have been examined as possible treatments for nat- 
ural rumen fluke infection in cattle and tapeworm infections in cats, dogs, sheep and chickens (Prasittirat et al. 1997).

Both bithionol and bithionol sulphoxide have been examined as treatments for numerous fish parasites and showed mixed results. Santamarina et al. (1991) observed limited toxicity and complete in vitro efficacy against Gyrodactylus sp. in rainbow trout Oncorhynchus mykiss at $12.5 \mathrm{mg} \mathrm{l}^{-1}$, with a minimum $20 \mathrm{mg} \mathrm{l}^{-1}$ reported as efficacious in vivo. Tojo et al. (1994b) stated that bithionol was efficacious in vivo against Ichthyobodo necator in rainbow trout at $25 \mathrm{mg} \mathrm{l}^{-1}$ for a $3 \mathrm{~h}$ freshwater bath on 2 consecutive days; however, higher concentrations exhibited some host toxicity. Moreover, Madsen et al. (2000) determined that bithionol at $0.1 \mathrm{mg} \mathrm{l}^{-1}$ was an effective treatment against trichodiniasis in European eels Anguilla anguilla, but found bithionol to have a relatively narrow therapeutic index. Bithionol was identified as being a potential candidate for the control of neoparmoebiasis with a demonstrated toxicity in vitro, although only 2 concentrations were tested (Powell et al. 2003). More recently, bithionol has displayed efficacy as a bath and oral treatment for Atlantic salmon experimentally challenged with Neoparamoeba spp., resulting in amoebic gill disease (AGD), at arbitary concentrations and dosages of 1 to $10 \mathrm{mg} \mathrm{l}^{-1}$ for bath treatments and $25 \mathrm{mg}$ $\mathrm{kg}^{-1}$ feed (Florent et al. 2007a,b, 2009), but more extensive in vitro efficacy testing is required for further development of this potential therapy.

In Tasmania, AGD is the primary disease affecting the production of Atlantic salmon Salmo salar, with the causative agent being the marine protozoan Neoparamoeba perurans (Young et al. 2007) which is cosmopolitan in its distribution (Powell et al. 2008). Commercial mitigation of AGD uses a freshwater bath for 2 to $3 \mathrm{~h}$, which removes the amoeba and promotes improved gill health (Parsons et al. 2001). However, the frequency of freshwater bathing has increased as it appears that each bath is proving less effective (Parsons et al. 2001), and the search for alternative treatments is ongoing. Of all the alternative treatments screened to date, few have achieved comparable results to freshwater. These include chloramine-T (Harris et al. 2004, 2005), hydrogen peroxide (Powell \& Clark 2003), levamisole (Findlay et al. 2000) and bithionol (Powell et al. 2003, Florent et al. 2007a,b, 2009). The familiarity of using freshwater baths and existing technology make commercial adoption of alternatives a slow process where no distinct advantage over the freshwater treatment is seen. However, the toxicity of bithionol and its sulphoxide derivative to the amoebae has not been clearly established, and lower concentrations may be effective at killing $\mathrm{Neo}$ paramoeba sp.
It is unknown if bithionol and bithionol sulphoxide exert the same toxic effects on Neoparamoeba spp. or whether they are capable of stimulating a therapeutic effect similar to that of freshwater by sloughing off affected gill tissue by effectively poisoning the epithelial tissue or if these chemicals are directly toxic to the amoeba. Bithionol is also known to interfere with oxidative metabolism and inhibition of NADH-fumerate reductase (Hamajima 1973, Reid et al. 2001); therefore, the potential to poison epithelia exists in addition to its effects on mitochondrial respiratory chain (Rew 1978, Harder 2002, Iglesias et al. 2002). Such treatments are beneficial if they are directly toxic to Neoparamoeba spp. at a lower concentration than is toxic to the fish. Therefore, the aim of the present study was to determine the effect of bithionol and bithionol sulphoxide on the survival of isolated gill amoebae in vitro. It was hypothesised that both bithionol and bithionol sulphoxide would decrease the survival of isolated gill amoeba when compared to seawater.

\section{MATERIALS AND METHODS}

Neoparamoeba spp. were isolated according to the frequently described method of Morrison et al. (2004). Briefly, the gills from donor AGD-affected Atlantic salmon were centrifuged at $400 \times g$ for 2 min in distilled water and rinsed with clean seawater 3 times, dislodging amoebae from the gills. The amoebae were allowed to adhere to Petri dishes for approximately $2 \mathrm{~h}$ at $18^{\circ} \mathrm{C}$ before being washed with seawater. The amoebae were allowed to re-adhere to Petri dishes overnight at $18^{\circ} \mathrm{C}$. The adherent cells were removed by the addition of $1 \mathrm{ml}$ Hanks balanced salts trypsin EDTA, washed with seawater, centrifuged at $400 \times g$ for $5 \mathrm{~min}$ and concentrated. An aliquot of amoebae isolate was stained with $0.5 \%$ trypan blue-seawater mix at a dilution of $1: 1$ and live amoeba (those not taking up the stain) counts were determined using a haemocytometer (Neubauer, BS 748). Three replicate counts were made, with 18 large squares counted per replicate.

The in vitro toxicity assay, modified from Powell et al. (2003), used isolated live amoebae that were adhered to flat-bottom, 96 well microtitre plates at a density of approximately 10000 cells in $150 \mu \mathrm{l}$ per well and allowed to adhere for $1.5 \mathrm{~h}$ at $18^{\circ} \mathrm{C}$ and then exposed to different treatments.

All test solutions were aerated to $100 \%$ air saturation and brought to $18^{\circ} \mathrm{C}$ before commencement of each experiment. Amoebae were exposed to either bithionol or bithionol sulphoxide (Sigma-Aldrich) at 0, 0.1, 0.51 , 5 or $10 \mathrm{mg} \mathrm{l}^{-1}$ in triplicate, repeated 8 times $(\mathrm{n}=24)$ per treatment over a $72 \mathrm{~h}$ exposure period. The number of 
live amoebae was determined at $0,24,48$ and $72 \mathrm{~h}$ of exposure using the trypan blue exclusion assay (described above). Bithionol and bithionol sulphoxide treatments were prepared making a stock solution using a mortar and pestle in order to create a suspension, as they are both insoluble in water, which was then diluted to make the necessary concentrations. Test concentrations are therefore reported as nominal concentrations based upon the amount of raw chemical added. There were several controls examined, including seawater (35\%, negative control), freshwater (dechlorinated municipal source, positive control) and alumina at $10 \mathrm{mg} \mathrm{l}^{-1}$ (Sigma-Aldrich), used to control for the low solubility of bithionol and bithionol sulphoxide in seawater and account for any surface effect the precipitates may have had on amoeba survival (after Powell et al. 2003).

A 1-way ANOVA was used to determine differences between assays. Where no significant differences were found, assays were pooled and a 2-way ANOVA was used to analyse means with time and treatment as factors. The interaction between time and treatment was examined first; if $p>0.05$, there was an interaction and the factors of time and treatment were combined and a Tukey's post hoc test conducted on the combined variable to identify where the differences occurred. Homogeneity was determined using a residual plot and Levene's test; where the data were not normally distributed or variance homogeneous, a square root transformation was used. A result was considered significant at $\mathrm{p} \leq 0.05$ and results are presented as means \pm standard error of the mean (SEM). All statistical analysis was conducted using SPSS for Windows ${ }^{\circledR}$ (version 15.0). Survival of amoeba was calculated as a percentage of seawater control (conducted at the same time) to ensure consistency among treatments:

$\%$ of seawater control $=$ $\left(\frac{\text { number of amoeba in treated group }}{\text { number of amoeba in sewater control group }}\right) \times 100$

\section{RESULTS}

Survival of amoebae in seawater controls was equal to or better than the initial concentrations observed at Time 0 and are given as $100 \%$ survival. Amoebae also survived when exposed to $10 \mathrm{mg} \mathrm{l}^{-1}$ alumina for the $72 \mathrm{~h}$ duration and were determined not to be significantly different from the seawater controls for both chemical treatments (bithionol: $F_{31,736}=413.356, \mathrm{p}<$ 0.001; bithionol sulphoxide: $F_{31,736}=280.358, \mathrm{p}<$ 0.00.1; Fig. 1). Amoebae numbers declined rapidly when exposed to freshwater, with a 94 and $96 \%$ relative reduction seen within the first $24 \mathrm{~h}$ when compared to the seawater control with bithionol and

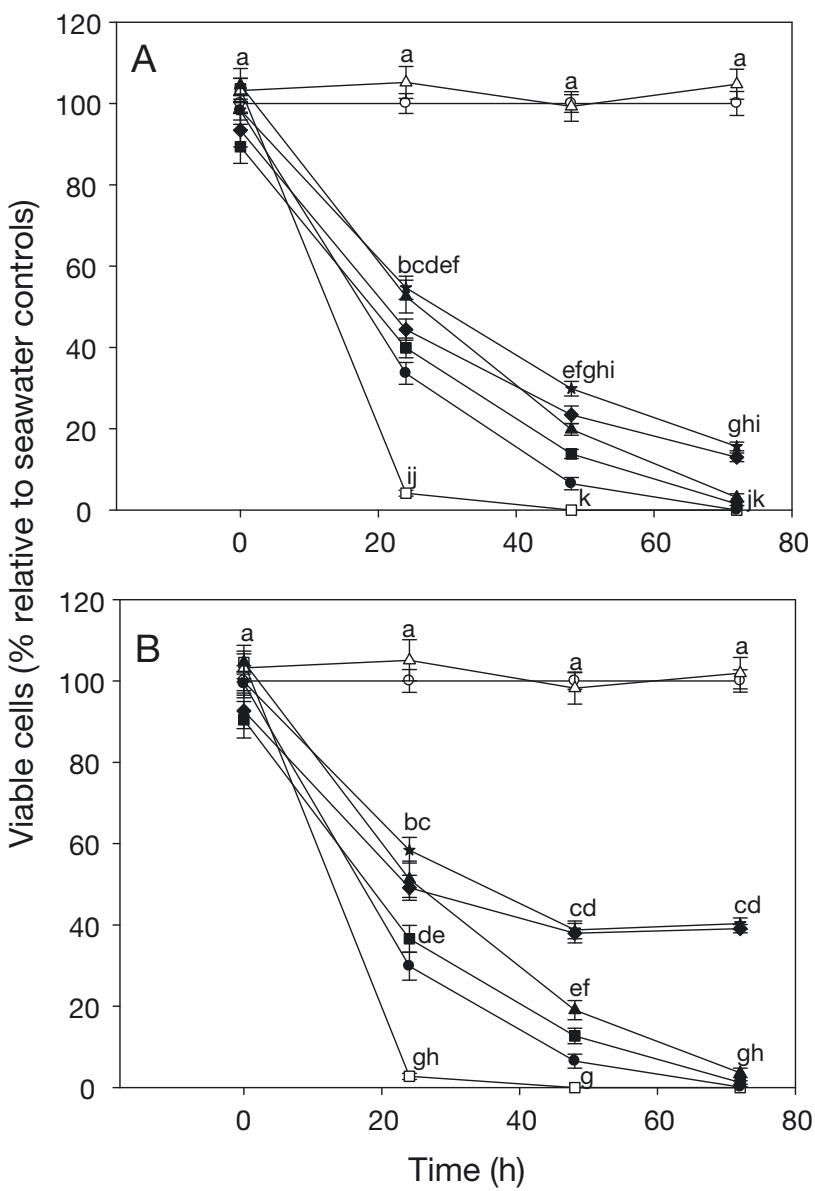

Fig. 1. Neoparamoeba spp. Effect of time and treatment on mean $( \pm$ SEM) number of viable isolated amoeba (as a percentage of the seawater control) when exposed to freshwater $(\square), 10 \mathrm{mg} \mathrm{l}^{-1}$ alumina $(\Delta)$, seawater $(O)$ or $(A)$ bithionol or $(B)$ bithionol sulphoxide at $0.1(\star), 0.5(\diamond), 1(\boldsymbol{\Delta}), 5(\mathbf{\square})$ and $10 \mathrm{mg}$ $\mathrm{l}^{-1}(\mathbf{O})(\mathrm{n}=24)$. Seawater controls remained at 10000 cells well $^{-1}$ and are presented as $100 \%$ survival. Common letter across both time and treatment indicates no significant difference using a Tukey's test ( $p>0.05)$

bithionol sulphoxide experimental treatments, respectively (Fig. 1).

Bithionol was effective at reducing amoebae numbers significantly at all concentrations and across all time points $\left(F_{31,736}=413.356, \mathrm{p}<0.001\right.$; Fig. 1$)$. When amoebae were treated with $10 \mathrm{mg} \mathrm{l}^{-1}$ of bithionol there was a $53 \%$ relative reduction within the first $24 \mathrm{~h}$ compared to seawater, and there were no surviving amoebae observed after $72 \mathrm{~h}$. Following $72 \mathrm{~h}$ of treatment, bithionol concentrations $>1 \mathrm{mg} \mathrm{l}^{-1}$ resulted in at least a $92 \%$ relative reduction in amoebae numbers compared with seawater, the same level of reduction observed for the freshwater group (Fig. 1). At the culmination of the assay, the greatest reduction in amoebae numbers compared to the seawater control (100, 95 and $92 \%$ ) was seen in the 10, 5 and $1 \mathrm{mg} \mathrm{l}^{-1}$ treat- 
ments, respectively. The lower concentrations of 0.5 and $0.1 \mathrm{mg} \mathrm{l}^{-1}$ of bithionol also significantly reduced amoebae numbers compared to the seawater control at $72 \mathrm{~h}$ by 87 and $82 \%$, respectively $\left(F_{31,736}=413.356, \mathrm{p}<\right.$ 0.001; Fig. 1).

Similarly, bithionol sulphoxide reduced amoebae numbers significantly when compared to the seawater control at all concentrations and time points $\left(F_{31,736}=\right.$ $280.358, \mathrm{p}<0.001$; Fig. 1). When treated with the highest concentration of bithionol sulphoxide $\left(10 \mathrm{mg} \mathrm{l}^{-1}\right)$, there was a $57 \%$ relative reduction in amoebae compared to seawater within the first $24 \mathrm{~h}$. After $72 \mathrm{~h}$, the relative reduction for the $10 \mathrm{mg} \mathrm{l}^{-1}$ treatment group was equal to that of the freshwater group at $99 \%$. Following $72 \mathrm{~h}$ of treatment, bithionol sulphoxide concentrations $>1 \mathrm{mg} \mathrm{l}^{-1}$ resulted in at least a $96 \%$ relative reduction in amoebae numbers compared with seawater, which was the same level of reduction observed for the freshwater group (Fig. 1). After $72 \mathrm{~h}$ exposure at the lower concentrations of bithionol sulphoxide of 0.1 and $0.5 \mathrm{mg} \mathrm{l}^{-1}$, amoebae numbers were reduced to only 59 and $60 \%$, respectively, significantly higher numbers than at the other bithionol sulphoxide concentrations $\left(F_{31,736}=\right.$ 280.358, p < 0.001; Fig. 1).

\section{DISCUSSION}

The present study demonstrates that bithionol and bithionol sulphoxide used in vitro were successful at reducing the number of surviving amoebae relative to seawater controls over the $72 \mathrm{~h}$ assay. Across all of the in vitro toxicity assays, the seawater control groups were equal to or better than the initial amoebae counts, indicating that conditions were appropriate to observe growth. Moreover, the reduction in amoeba survival in the bithionol and bithionol sulphoxide treatments was unlikely to be a surface effect due to low chemical solubility, since the numbers of surviving amoeba in the alumina groups (particulate control) were equal to those in the seawater controls. This indicated that the particulate matter in the well did not adversely affect amoebae survival over the $72 \mathrm{~h}$ period, a result consistent with Powell et al. (2003). For bithionol and bithionol sulphoxide, the lowest concentration capable of killing a significant number of amoeba (>50\%) over $72 \mathrm{~h}$ was 0.1 and $1 \mathrm{mg} \mathrm{l}^{-1}$, respectively. Given the low apparent solubility of both bithinol and bithionol sulphoxide, it is likely that the present study overestimates the concentrations required to kill Neoparamoeba spp. However, based on a previous study, these concentrations are lower than those toxic to salmon in fresh or saltwater (Florent et al. 2007a).

When comparing freshwater treatments to the seawater controls, a 94 and $96 \%$ relative reduction in amoebae viability was observed, respectively. Amoebae numbers declined rapidly in freshwater, consistent with other studies (Howard \& Carson 1993, Powell \& Clark 2003), indicating that freshwater remains the most effective fast-acting treatment. However, following the $72 \mathrm{~h}$ toxicity assay, bithionol and bithionol sulphoxide both successfully reduced amoebae numbers to levels similar to those found with freshwater treatments at concentrations $>1 \mathrm{mg} \mathrm{l}^{-1}$. At lower concentrations $\left(<1 \mathrm{mg} \mathrm{l}^{-1}\right)$, bithionol was successful in reducing amoebae numbers, albeit not as effectively as freshwater. Bithionol sulphoxide at the lower concentrations of 0.1 and $0.5 \mathrm{mg} \mathrm{l}^{-1}$ was the least effective treatment, reducing amoebae numbers by $50 \%$. Furthermore, the results indicated that both chemicals were active at reducing the numbers of surviving amoeba throughout the entire $72 \mathrm{~h}$ time period.

To date, the only commercially used treatment for AGD is freshwater bathing. Several compounds have been screened for in vitro toxicity including various antimicrobials, antiparasitics, disinfectants and detergents with varying success. Of all the chemicals screened, only a small number have achieved comparable results to freshwater, including chloramine-T (Harris et al. 2004, 2005), hydrogen peroxide (Powell \& Clark 2003), levamisole (Findlay et al. 2000) and bithionol (bath treatment, Florent et al. 2007a; oral treatment, Florent et al. 2007b, 2009). However, some of these treatments were most effective when added to a freshwater bath, hence, still maintaining reliance upon freshwater bathing to treat AGD.

Studies examining the chemical control and treatment of Neoparamoeba spp. (Powell et al. 2003), Hexamita salmonis (Tojo \& Santamarina 1998a), Gyrodactylus spp. (Tojo \& Santamarina 1998b), Icthyobodo necator (Tojo et al. 1994a, Tojo \& Santamarina 1998c), Microcotyle sebastis (Kim \& Choi 1998), Pseudodctylogyrus spp. (Buchmann et al. 1992) and Trichodina jadranica (Madsen et al. 2000) have all examined bithionol and, in some cases, bithionol sulphoxide in vitro and in vivo as bath and oral treatments. When examining theses studies, bithionol exhibited variable toxicity depending upon the parasite species being tested; however, in general it was reported to be effective in vitro and in vivo, as both bath and oral treatments reduced parasite loads dramatically. However, with the scale and intensity of salmonid farming occurring in Tasmania, a bithionol bath treatment would be impractical. The low solubility and high cost would require large quantities for effective treatment and pose difficulties with regard to disposal of the bath water. The low concentrations that appear toxic to amoebae in the present study (as low as $1 \mathrm{mg} \mathrm{l}^{-1}$ ) make both bithionol and bithionol sulphoxide attractive as oral treatments. Florent et al. (2007b) have demon- 
strated that oral treatment of Atlantic salmon affected by AGD with bithionol at a concentration of $25 \mathrm{mg} \mathrm{kg}^{-1}$ feed could reduce the severity of infection by approximately $50 \%$. Bithionol and bithionol sulphoxide have both been used as a successful treatment for numerous human disease, including paragonimiasis (oriental lung fluke) and fasciolasis (liver fluke) (Yang \& Lin 1967, Bacq et al. 1991), with bithionol sulphoxide having better anthelminthic activity in rats (Meshi et al. 1970). In the present study, bithionol and bithionol sulphoxide exhibited similar reductions at high concentrations; however, at concentrations of $0.5 \mathrm{mg} \mathrm{l}^{-1}$ or lower, bithionol sulphoxide was not as effective as bithionol.

Bithionol and bithionol sulphoxide are not currently licensed for use in fish as therapeutics in Australia. Bithionol is used as an ingredient in deodorants, shampoos and surgical soaps; however, this has been stopped by the US Food and Drug Administration for safety reasons (FDA 2002), even though bithionol is currently being investigated as a therapeutic for use in treating human paragonimiasis and fascioliasis (CDC 2008). Currently, the cost of bithionol is 8 times greater than that of bithionol sulphoxide and the likelihood of industry adoption should be considered prior to approaching regulatory bodies.

The use of this in vitro toxicity test has allowed the screening of compounds for potential toxicity toward Neoparamoeba spp. Stage I of drug screening, the development of single- and multi-day in vitro toxicity assays, has allowed for the bulk testing of numerous disinfectants, antibiotics and antiprotozoal drugs (Powell et al. 2003, 2005, 2007). To date, few candidate drugs have progressed to Stage II of testing, whereby salmon are either bathed or offered drug-coated feed and subsequently experimentally challenged with Neoparamoeba spp. to determine the fish toxicity and efficacy for reducing the onset of AGD (Powell et al. 2003, 2007). Bithionol has successfully completed both of these stages (Stage I, Powell et al. 2003, present study; Stage II, Florent et al. 2007a,b, 2009). A study has shown that bithionol may be more effective at high infection pressures, such as that in the laboratory trial or at times of a rapid onset of disease, as opposed to a low infection pressures seen typically with chronic conditions of disease on farms (Florent et al. 2009). Few treatments have moved on to Stage III testing involving field trials (Powell et al. 2007), except for chloramine-T (Harris et al. 2004, 2005) and Aquacite/ Betabec $^{\mathrm{TM}}$ (Powell et al. 2008). None of the treatments tested have been adopted commercially to date. This 3-tiered approach has allowed for a strategic system of screening and identifying candidate drugs from a large pharmacopeia, whilst maintaining effective resource management. Bithionol and bithionol sulphox- ide both demonstrate a high degree of toxicity to Neopararmoeba spp. in vitro, suggesting that sufficiently low concentrations as may be measured from the inclusion of this drug with feed are effectively toxic to the amoeba.

Acknowledgements. This research formed part of a project of the Aquafin CRC, and received funds from the Australian Government's CRC Programme, Fisheries R \& D Corporation and other CRC participants.

\section{LITERATURE CITED}

Bacq Y, Besnier JM, Duong TH, Pavie G, Metman EH, Choutet P (1991) Successful treatment of acute fascioliasis with bithionol. Hepatology 14:1066-1069

Buchmann K, Felsing A, Slotvd HC (1992) Effects of metrifonate, sodium chloride and bithionol on an European population of the gill parasitic monogeneans Pseudodactylogyrus spp. and the host Anguilla anguilla. Bull Eur Assoc Fish Pathol 12:57-60

CDC (Centers for Disease Control and Prevention) (2008) Products distributed by the Centers for Disease Control and Prevention. CDC, National Center for Preparedness, Detection, and Control of Infectious Diseases, Atlanta, GA, available at www.cdc.gov/ncidod/srp/drugs/formulary. html

FDA (US Food and Drug Administration) (2002) Guidance for FDA staff and industry. Compliance policy guides manual. FDA, Silver Spring, MD, available at www.fda.gov/ OHRMS/DOCKETS/98fr/02D-0242_gdl0001.pdf

Findlay VL, Zilberg D, Munday BL (2000) Evaluation of levamisole as a treatment for amoebic gill disease of Atlantic salmon, Salmo salar L. J Fish Dis 23:193-198

> Florent RL, Becker JA, Powell M (2007a) Evaluation of bithionol as a bath treatment for amoebic gill disease caused by Neoparamoeba spp. Vet Parasitol 144:197-207

Florent RL, Becker JA, Powell MD (2007b) Efficacy of bithionol as an oral treatment for amoebic gill disease in Atlantic salmon Salmo salar (L.). Aquaculture 270:15-22

Florent RL, Becker JA, Powell MD (2009) Further development of bithionol therapy as a treatment for amoebic gill disease in Atlantic salmon, Salmo salar L. J Fish Dis 32: 391-400

$>$ Hamajima F (1973) Metabolism of lung fluke genus Paragonimus. VII. Action of bithionol on glycolytic and oxidative metabolism of adult worms. Exp Parasitol 34:1-11

Harder A (2002) Chemotherapeutic approaches to trematodes (except schistosomes) and cestodes: current level of knowledge and outlook. Parasitol Res 88:587-590

Harris JO, Powell MD, Attard M, Green TJ (2004) Efficacy of chloramine- $\mathrm{T}$ as a treatment for amoebic gill disease (AGD) in marine Atlantic salmon (Salmo salar L.). Aquac Res 35:1448-1456

Harris JO, Powell MD, Attard MG, DeHayer L (2005) Clinical assessment of chloramine-T and freshwater as treatments for the control of gill amoebae in Atlantic salmon, Salmo salar L. Aquac Res 36:776-784

Howard T, Carson J (1993) Are there alternatives to freshwater treatment of AGD? In: Valentine P (ed) Proceedings of the SALTAS Research and Development Review Seminar. SALTAS, Hobart, Tasmania, p 81-87

Iglesias R, Parama A, Alvarez MF, Leiro J, Sanmartin ML (2002) Antiprotozoals effective in vitro against the scutic- 
ociliate fish pathogen Philasterides dicentrarchi. Dis Aquat Org 49:191-197

Kim KH, Choi ES (1998) Treatment of Microcotyle sebastis (Monogenea) on the gills of cultured rockfish (Sebastes schelegeli) with oral administration of mebendazole and bithionol. Aquaculture 167:115-121

Madsen HCK, Buchmann K, Mellergaard S (2000) Treatment of trichodiniasis in eel (Anguilla anguilla) reared in recirculation systems in Denmark: alternatives to formaldehyde. Aquaculture 186:221-231

Meshi T, Yoshikawa M, Sato Y (1970) Metabolic fate of bis(3,5-dichloro-2-hydroxyphenyl)-sulfoxide (bithionol sulfoxide). Biochem Pharmacol 19:1351-1361

Morrison RN, Crosbie PBB, Nowak BF (2004) The induction of laboratory-based amoebic gill disease revisited. J Fish Dis 27:445-449

Parsons H, Nowak B, Fisk D, Powell M (2001) Effectiveness of commercial freshwater bathing as a treatment against amoebic gill disease in Atlantic salmon. Aquaculture 195: 205-210

Powell MD, Clark GA (2003) In vitro survival and the effect of water chemistry and oxidative chemical treatments on isolated gill amoebae from AGD-affected Atlantic salmon. Aquaculture 220:135-144

Powell M, Green T, Plaisted C (2003) A cell culture assay for the in vitro efficacy testing of amoebocidal compounds against Neoparamoeba pemaquidensis. Bull Eur Assoc Fish Pathol 23:291-296

Powell MD, Attard M, Harris JO, Roberts SD, Leef MJ (2005) Why fish die: the treatment and pathophysiology of AGD. FRDC Project no. 2001/205, University of Tasmania, Launceston

Powell MD, Becker JA, Ransome J, Florent RL, Jones M (2007) Commercial AGD and salmon health. FRDC Project no. 2004/213, University of Tasmania, Launceston

Powell MD, Mlynarski H, Becker JA, Mackie JA (2008) Effects of oral administration of Aquacite ${ }^{\mathrm{TM}}$ and Betabec $^{\mathrm{TM}}$, two commercial b-glucan based nutritional supplements in Atlantic salmon (Salmo salar) during an outbreak of amoebic gill disease. Fiskehelse 10:30-39

Prasittirat P, Nithiuthai S, Ruengsuk K, Kitwan P, Bunmatid C, Roopan S, Itagaki H (1997) Efficacy of bithionol sulfoxide, niclosamide and fenbendazole against natural rumen fluke infection in cattle. Helminthologia 34:155-157

Reid L, Clothier RH, Khammo N (2001) Hydrogen peroxide induced stress in human keratinocytes and its effect on bithionol toxicity. Toxicol In Vitro 15:441-445

Editorial responsibility: Dieter Steinhagen,

Hannover, Germany
Rew RS (1978) Mode of action of common anthelmintics. J Vet Pharmacol Ther 1:183-197

Santamarina MT, Tojo J, Ubeira FM, Quinteiro P, Sanmartín ML (1991) Anthelmintic treatment against Gyrodactylus sp. infecting rainbow trout Oncorhynchus mykiss. Dis Aquat Org 10:39-43

Sawatari S, Hamajima F (1967) Effects of isothiocyanates and bithionol on Paragonimus westermani (Kerbert, 1878) in vitro. Kisechugaku Zasshi 16:174-178

Takeuchi T, Kobayashi S, Kawasaki H (1984) Entamoeba histolytica inhibition in vitro by bithionol of respiratory activity and growth. Exp Parasitol 58:1-7

> Tojo JL, Santamarina MT (1998a) Oral pharmacological treatments for parasitic diseases of rainbow trout Oncorhynchus mykiss. I: Hexamita salmonis. Dis Aquat Org 33: $51-56$

Tojo JL, Santamarina MT (1998b) Oral pharmacological treatments for parasitic diseases of rainbow trout Oncorhynchus mykiss. II: Gyrodactylus sp. Dis Aquat Org 33: 187-193

Tojo JL, Santamarina MT (1998c) Oral pharmacological treatments for parasitic diseases of rainbow trout Oncorhynchus mykiss. III: Ichthyobodo necator. Dis Aquat Org 33:195-199

Tojo J, Santamarina MT, Ubeira FM, Leiro J, Sanmartin ML (1994a) Attempts to control Ichthyobodo necator in rainbow trout (Oncorhynchus mykiss) by bath treatment. Bull Eur Assoc Fish Pathol 14:12-15

Tojo JL, Santamarina MT, Leiro J, Ubeira FM, Sanmartin ML (1994b) Pharmacological treatments against Ichthyobodo necator (Henneguy, 1883) in rainbow trout, Oncorhynchus mykiss (Walbaum). J Fish Dis 17:135-143

Yang SP, Lin CC (1967) Treatment of paragonimiasis with bithionol and bithionol sulfoxide. Dis Chest 52:220-232

Yokogawa $M$, Yoshimura $H$, Okura $T$, Sano $M$, Tsuji $M$, Iwasaki M, Hirose H (1961a) Chemotherapy of paragonimiasis with bithionol. II. Clinical observations on the treatment of bithionol. Kisechugaku Zasshi 10:317-327

Yokogawa M, Yoshimura H, Sano M, Okura T and others (1961b) Chemotherapy of paragonimiasis with bithionol. I. Experimental chemotherapy on the animals infected with Paragonimus westermani or P. ohirai. Kisechugaku Zasshi 10:302-316

Young ND, Crosbie PBB, Adams MB, Nowak BF, Morrison RN (2007) Neoparamoeba perurans n. sp., an agent of amoebic gill disease of Atlantic salmon (Salmo salar). Int J Parasitol 37:1469-1481

Submitted: August 1, 2008; Accepted: July 14, 2010

Proofs received from author(s): September 10, 2010 